\title{
Synthesis of NiO/Activated Carbon Composites and Their Application as Electrode Materials for Capacitors
}

\author{
Jing-Pei Cao ${ }^{l, *}$, Shan $\mathrm{He}^{l}$, Yan $\mathrm{Wu}^{1}$, Xiao-Yan Zhao ${ }^{1}$, Xian-Yong Wei ${ }^{l}$ and Takayuki Takarada ${ }^{2}$ \\ ${ }^{1}$ Key Laboratory of Coal Processing and Efficient Utilization (Ministry of Education), China \\ University of Mining \& Technology, Xuzhou 221116, Jiangsu, China \\ ${ }^{2}$ Division of Environmental Engineering, Gunma University, 1-5-1 Tenjin-cho, Kiryu 376-8515, Japan \\ *E-mail: caojingpei@cumt.edu.cn, beyondcao@hotmail.com, beyondcao_2000@163.com
}

doi: $10.20964 / 2017.04 .39$

Received: 9 January 2017 / Accepted: 21 February 2017 / Published: 12 March 2017

\begin{abstract}
Electrochemical capacitor (EC) based on NiO/activated carbon (AC) composite electrodes was investigated in this work to improve its electrochemical performance. NiO/AC composites were prepared as anode, while HyperCoal-based ACs were used as cathode for EC. The composites were characterized by means of X-ray diffraction and scanning electron microscopy. The porosity of HyperCoal-based ACs was characterized by $\mathrm{N}_{2}$ adsorption-desorption analyses. The electrochemical characterization of capacitor was examined using galvanostatic charge-discharge in $1 \mathrm{M}$ and $8 \mathrm{M} \mathrm{KOH}$ electrolyte solution. The results show that NiO/AC composite electrodes exhibit a good electrochemical performance with a maximum specific capacitance $\left(\mathrm{C}_{\mathrm{g}}\right)$ of $214.48 \mathrm{~F} \mathrm{~g}^{-1}$ at the chargedischarge current density of $40 \mathrm{~mA} \mathrm{~g}^{-1}$ in $1 \mathrm{M} \mathrm{KOH}$ electrolyte. Meanwhile, the $\mathrm{C}_{\mathrm{g}}$ increases gradually with the increase of $\mathrm{NiO}$ content. In addition, the $\mathrm{C}_{\mathrm{g}}$ of $\mathrm{EC}$ prepared in $8 \mathrm{M} \mathrm{KOH}$ aqueous is higher than that of EC prepared in $1 \mathrm{M} \mathrm{KOH}$ aqueous until the content of $\mathrm{NiO}$ reaches up to $55.6 \%$.
\end{abstract}

Keywords: electrochemical capacitor, $\mathrm{NiO}$, activated carbon, composite electrodes, specific capacitance.

\section{FULL TEXT}

(C) 2017 The Authors. Published by ESG (www.electrochemsci.org). This article is an open access article distributed under the terms and conditions of the Creative Commons Attribution license (http://creativecommons.org/licenses/by/4.0/). 